\title{
Coulisses
}

Revue de théâtre

\section{Moralités de Mystère Bouffe de Dario Fo par le Théâtre universitaire de Franche-Comté}

Entretien avec Stéphane, membre du TUFC

\section{Stéphane et Rédaction}

\section{OpenEdition}

Journals

Édition électronique

URL : http://journals.openedition.org/coulisses/1604

DOI : $10.4000 /$ coulisses. 1604

ISSN : 2546-9460

\section{Éditeur}

Presses universitaires de Franche-Comté

\section{Édition imprimée}

Date de publication : 1 novembre 1990

Pagination : np

ISSN : 1150-594X

Référence électronique

Stéphane et Rédaction, « Moralités de Mystère Bouffe de Dario Fo par le Théâtre universitaire de Franche-Comté », Coulisses [En ligne], 2 | Automne 1990, mis en ligne le 04 juillet 2017, consulté le 25 octobre 2019. URL : http://journals.openedition.org/coulisses/1604 ; DOI : 10.4000/coulisses.1604

Ce document a été généré automatiquement le 25 octobre 2019

Coulisses 


\section{Moralités de Mystère Bouffe de Dario Fo par le Théâtre universitaire de Franche-Comté}

Entretien avec Stéphane, membre du TUFC

Stéphane et Rédaction

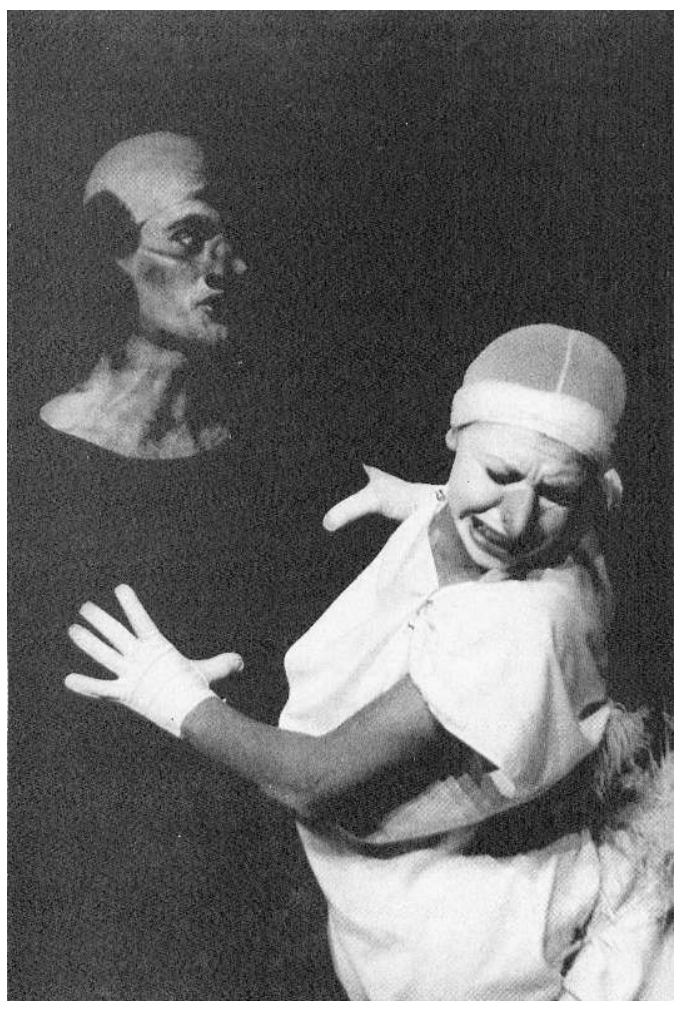

(c) Collectif Photo BVOJ 90.

Q. : Pourquoi jouez-vous à BVOJ ? 
2 S. : Lorsque le Théâtre de Poche a demandé de venir jouer, nous avons été très heureux, mais notre spectacle Mystère Bouffe de Dario Fo, comporte douze tableaux et dure trois heures! Nous en avons donc choisi trois en fonction de la disponibilité des étudiants et de la configuration des lieux.

Boniface VIII n'a qu'un seul rôle, Les noces de Cana, la Moralité de l'aveugle et du boiteux, deux. Notre spectacle s'accordait bien avec celui qui le précédait. Clown est-ce que?

Q. : Quel est le thème général du spectacle?

S.: Dario Fo s'est inspiré des pièces du Moyen-Âge. Il dénonce de façon burlesque l'oppression de l'homme par l'homme, le pouvoir, l'église, mais il respecte la figure du Christ, porteur d'espérance, voire de délivrance.

6 Dans Les Noces de Cana, j'interprète le rôle d'un ivrogne. Un ange, sans doute mon ange gardien, veut raconter une histoire au public, et moi je tiens à lui faire part de "ma merveilleuse saoûlerie". Finalement, je chasse l'ange et peux narrer comment Jésus, à la demande de sa mère, a transformé l'eau en vin lors d'un banquet de mariage. Grâce à ce miracle, faire la fête n'est plus un péché, au contraire! La fête devient l'antichambre du paradis où les besoins matériels sont assouvis et les besoins spirituels comblés.

\section{De la représentation a la lecture}

7 Lire "Mystère Bouffe » de Dario Fo, c'est entrer de plain pied dans l'absurdité de l'existence humaine, de ses douleurs, de ses angoisses, de sa violence, de l'inextricable où le paradoxe est roi.

8 Aussi loin que vont la perception et la connaissance de l'homme vis-à-vis de l'homme, se trame l'angoisse de ce que l'on ne comprend pas, n'appréhende pas. Impuissant, assujetti de la naissance jusqu'à la mort, en somme : « la mise à merci sans merci ». Qu'a fait l'homme devant cet écrasant horizon du négatif définitif ? Qu'a fait l'homme ?

Il a essayé, s'est efforcé de s'appuyer, de s'étayer, de se ménager un moyen, des moyens, quelque chose lui permettant non pas d'échapper à l'inéluctable, mais de l'aider à le supporter et quelquefois même à l'oublier.

11 Alors, lentement, mais avec une extraordinaire constance, quels que soient les régions, les contrées, les pays, les races, on trouve à travers coutumes et mœurs cet effort constant, courageux, parfois téméraire, continu, pour subir et supporter l'insupportable.

12 Voici venir, les jeux, les danses, les chants, les spectacles, le mime et le théâtre. C'est le conteur, c'est le jongleur. C'est la grande féerie qu'amène l'art de celui qui sait dire les choses telles qu'elles sont. Dans une telle détresse, au milieu du désastre des corps soumis à la faim, au froid, aux maladies, à la misère absolue, l'esprit cependant demeure, sans oublier son enveloppe charnelle, seul élément tangible de sa vie, l'homme s'exaspère de sa subordination aux lois naturelles à laquelle s'ajoute celle des lois faites par eux, cependant.

Ainsi, on trouve dans La moralité de l'aveugle et du boiteux :

- le thème de l'injustice de la naissance - Pourquoi aveugle ? Pourquoi boiteux ? 
15 - le thème de la dépendance. Nul ne saurait se passer d'autrui. Or, dépendre d'un autre, n'est-ce pas nier la liberté?

16 - le thème de l'exploitation de l'homme par ceux-là même qui sont exploités.

17 - l'accoutumance à sa misère: mieux vaut rester comme on est c'est-à-dire l'accoutumance à soi.

18 - l'incapacité de l'homme d'échapper à son destin : changer c'est tomber « de Charybde en Scylla ».

19 - la diversité des tempéraments. L'un refuse le miracle : le boiteux, l'autre le désire : l'aveugle.

20 - l'évaluation de la pesanteur des misères : être aveugle, être boiteux, quel est le pire?

21 - le boiteux peut espérer une amélioration de son sort, béquille, petite voiture, etc., l'aveugle, non.

22 - leurs prises de positions en résultent: sans béquilles comment gagnerai-je ma vie? (déjà le chômage) : l'un refuse le miracle, s'en désole. Avec la vue, c'est la révélation du monde, l'autre remercie et s'en émerveille.

23 Toujours ainsi, l'homme est à disposition. Il ne peut, en quoi que ce soit, échapper aux conditions d'assujetti, d'asservi, échapper à sa vie d'efforts, de difficultés, de désillusions, de cruauté, de perversité morale ou/et physique même devant le miracle.

24 Le hasard a joué et le hasard c'est ce qui dépasse, ne s'appréhende pas, ce qui s'exerce sur toutes choses d'une manière inexplicable, souveraine, absolue, spontanée, inattendue. Citons entre autres: les rencontres, la maladie, la mort avec toute la diversité qui signe chaque vie.

25 La nature a bien aidé dans ce sens avec ses manifestations spectaculaires imposantes ou insidieuses. Stupéfaits, les hommes effrayés, se sont inclinés, comme devant les forces, dites occultes. Peur, ignorance, tendance naturelle à chercher hors l'ordinaire, dans l'au-delà, une espérance impossible ici-bas ont joué, d'où l'appel au divin, dieux multiples ou dieu unique, chacun a présenté sa conception de l'infini prodigieux.

26 Les puissants se sont emparés du phénomène existant en tout homme et en ont fait un moyen supplémentaire d'assujettissement, ajoutant aux angoisses terrestres celles des deux « l'enfer ».

27 Si bien que dans ce texte "moralité de l'aveugle et du boiteux, on voit, infinie l'hommage rendu à la puissance souveraine de l'inexplicable, le fils de Dieu a accompli un miracle! Un miracle, oui ou non ? La tendance à croire amène à une médiatisation de l'homme, justifiant la formule = La religion est l'opium du peuple ». 